\title{
TRIUNFOS EN TIEMPOS DE TRANSICIÓN. ACTORES DE VOCACIÓN POPULAR EN LAS ELECCIONES VENEZOLANAS DE 1998
}

\author{
Margarita López Maya* y Luis E. Lander***
}

\section{INTRODUCCIÓN}

En noviembre y diciembre de 1998 los venezolanos hemos participado en uno de los procesos electorales más impactantes, complejos y apasionantes en lo que va del período de nuestra democracia política. En los comicios regionales y del Congreso Nacional celebrados el 6 de noviembre, se acentuó el universo plural de la representación política venezolana ya surgido en procesos anteriores, inclinándose esta vez la balanza a favor de actores de vocación popular, aglutinados en el llamado Polo Patriótico (PP). Entre ellos, el Movimiento V República (MVR), una organización con poco más de año y medio de vida, se convirtió en el segundo partido del país y el Patria Para Todos (PPT), con el mismo tiempo de nacimiento, se adjudicó tres gobernaciones y se colocó en un sexto lugar de la lista de organizaciones políticas. El 8 de diciembre, el teniente coronel (r) Hugo Chávez Frías, el jefe de la fracasada insurrección del 4 de febrero de 1992 y líder fundador del MVR, alcanzaba la Presidencia con una de las votaciones más altas alcanzadas por candidato alguno en la historia electoral. De segundo arribaba el candidato de otra organización emergente llamada Proyecto Venezuela, Henrique Salas Römer, mientras los partidos ejes del tradicional bipartidismo del país, Acción Democrática y el socialcristiano COPEI, después de algunos episodios poco comprensibles desde la racionalidad política, abandonaron la carrera para apoyar la candidatura de Salas Römer, hasta cinco días antes, su adversario político. La alianza de última hora se autodefinió como el Polo Democrático.

El significativo avance regional y nacional del Polo Patriótico $(P P)$ en noviembre, así como la contundente victoria presidencial de Chávez Frías en diciembre, tienen su explicación en un complejo entramado de condiciones y causas que en este artículo ubicaremos en dos dimensiones analíticas distintas. Por una parte, presentaremos como telón de fondo, la persistencia por ya cuatro lustros de un contexto de crisis global y transición de la sociedad venezolana, que en el año de 1998 se vio agravado en sus aspectos socioeconómicos por la baja de los precios petroleros en el mercado mundial y la consiguiente crisis fiscal. La segunda dimensión está constituida por la dinámica generada entre los actores políticos e institucionales al calor de la propia coyuntura electoral, donde las agrupaciones emergentes de vocación popular agrupadas en el Polo Patriótico demostraron mayor y mejor capacidad para mantenerse en sintonía con el sentir de las mayorías, y hasta se vieron favorecidos por las acciones desarrolladas por sus adversarios, tanto por los actores tradicionales como por otros actores emergentes.

\section{EL CONTEXTO: UN ELECTORADO FRUSTRA- DO Y RADICALIZADO}

Durante el período constitucional del presidente Rafael Caldera (1994-1999), persistió la ya larga dificultad por parte de la sociedad para encontrar un modelo económico nuevo que superara al modelo rentista-petrolero venezolano agotado desde finales de los años setenta (Baptista, 1989). Como parte de ello, el período comenzó con una aguda crisis financiera y fiscal y finalizó con otra crisis fiscal, que si bien no alcanzaría las magnitudes de la de 1994, determinaría un nueva agudización del empobrecimiento de la población y la consiguiente percepción pesimista y crítica por parte de los venezolanos de lo que había sido el desempeño económico gubernamental durante esos años. A este contexto socioeconómico se sobrepuso la permanencia del deterioro político-institucional, visible tanto a través de las mil facetas del deterioro de las instituciones del Estado y los servicios públicos, como en la eficaz acción de los partidos tradicionales para neutralizar prácticamente todas las iniciativas de cambio político que venían siendo propugnadas por actores emergentes y la ciudadanía en general desde los años ochenta. Esbocemos rápidamente este contexto que propició la conformación de un electorado más dispuesto que en

\footnotetext{
Centro de Estudios del Desarrollo de la Universidad Central de Venezuela.

Facultad de Ciencias Económicas y Sociales de la Universidad Central de Venezuela.
} 
el pasado a buscar en los comicios de 1998 un cambio profundo al orden político de la sociedad.

\section{a) El derrumbe de los precios petroleros y las condicio- nes sociales del período}

Cuando el doctor Caldera accede al gobierno en febrero de 1994 la sociedad venía de vivir un intento de restructuración económica, conocido como el Gran Viraje, bajo la orientación y la tutela de los organismos financieros multilaterales. Fue la primera iniciativa coherente de superar la crisis del agotado modelo rentista petrolero por la vía de las doctrinas neoliberales (Lander, 1996). Este intento, aunque alcanzó en los primeros años algunos resultados macroeconómicos positivos (Naím, 1993), desencadenó una crisis sociopolítica e institucional de vastas proporciones, de la cual la victoria de Caldera en los comicios de 1993 fue uno de sus resultados (López Maya y Lander, 1996).

El presidente Caldera resultó electo con las promesas explícitas de desarrollar un modelo económico distinto al pautado desde el Fondo Monetario Internacional y el Banco Mundial (Caldera, 1993). Este ofrecimiento, sin embargo, se verá frustrado. Pocos días antes de la toma de posesión del nuevo gobierno, el gobierno de emergencia del doctor Ramón J. Velásquez se vio obligado a intervenir al principal banco del país, el Banco Latino. Esta medida fue interpretada por el Presidente entrante como "un coletazo de la crisis moral y económica" de los años anteriores (Caldera en Panorama, 3-2-1994: 1-9). No obstante, significó el inicio de la más severa crisis financiera que haya padecido el país a lo largo del siglo, y que de acuerdo a informaciones del Banco Central, implicó para el año 1994 la inyección de recursos por parte del Estado al sistema bancario equivalente al 10\% del PIB (El Nacional, 20-12-1998, E-6). El costo financiero que significó para el fisco esta crisis limitó severamente la capacidad de diseñar y poner en práctica un modelo económico propio en un contexto internacional donde las políticas de los organismos multilaterales han sido hegemónicas. Luego de dos años de erráticos intentos por definir una política económica, en abril de 1996 el Presidente anunció la implementación de la Agenda Venezuela, un versión atenuada del Gran Viraje de Carlos Andrés Pérez .

Para 1997, la combinación de un aumento en el precio promedio de la cesta petrolera venezolana en los circuitos internacionales, una mayor recaudación impositiva en el sector no petrolero, y una mayor disciplina en el gasto público, permitieron una recuperación de las cifras macroeconómicas. Se registró en relación al año anterior un crecimiento del PIB de $5,12 \%$ a precios constantes, un superávit en las finanzas públicas de 1,6\% del PIB, la inflación bajó a 50,04\% (en 1996 había alcanzado el 99,87\%) y las reservas al cerrar el año alcanzaban a $\$ 17.745$ millones (IESA, 1999). Esto creó una atmósfera, principalmente entre los agentes económicos, de alivio y moderado optimismo que presagiaba el inicio de un proceso de recuperación y resolución de la larga crisis económica vivida en el país. No obstante, desde octubre de 1997, comenzaría lo que a la postre ha significado una debacle de los precios del barril petrolero en el mercado internacional. Poco antes de finalizar el año de 1998, el
Banco Central calculó que la caída del precio promedio de la canasta petrolera de exportación venezolana con relación al año anterior fue de 34,1\% (El Nacional, 20-11-1998: E6). Ello obligó a sucesivos ajustes del precio promedio de realización del petróleo venezolano para efecto de los cálculos fiscales, desde un estimado inicial en la Ley de Presupuesto de $\$ 15,50$ por barril a $\$ 11,50$ al finalizar el año (El Nacional, 20-11-1998: E-6) ${ }^{2}$. Esta severa reducción produjo una disminución en los ingresos fiscales petroleros del orden de los $\$ 7.000$ millones, lo cual obligó a un recorte del gasto público de aproximadamente $\$ 2.300$ millones y un déficit fiscal de al menos 5\% del PIB (Petkoff en El Universal, 20-11-1998: 2-1). El moderado optimismo con que cerró el año 1997, a lo largo del año 1998 se fue trastocando en pesimismo y cuestionamiento al desempeño gubernamental en política económica ${ }^{3}$.

En el plano social, el gobierno de Caldera no logró superar los gravísimos problemas que viene arrastrando la sociedad venezolana desde hace por lo menos dos décadas, los cuales han tendido a profundizarse a partir de 1989 y 1996 con la aplicación de los programas de ajuste ${ }^{4}$. Con una inflación acumulada de más de $800 \%$, que ha sido la más alta de período constitucional alguno, los principales indicadores sociales del gobierno de Caldera han continuado su tendencia al deterioro. Para junio de 1997, del total de 4.740 .250 de hogares, 2.122.016 se encontraban en situación de pobreza, 895.542 de ellas en situación de pobreza extrema ( $\mathrm{Sic}$, 1997). Es decir el 44,76\% de los hogares venezolanos no cuentan con el ingreso para satisfacer sus necesidades básicas, y el 18,89\% no llegan a cubrir sus necesidades alimentarias. El Programa Venezolano de Acción Educación en Derechos Humanos (PROVEA) calcula para 1998 que el $15 \%$ de los venezolanos se encuentran en condición de pobreza atroz, entendiendo por ello a quienes viven a la intemperie y están excluidos de cualquier política social ( $E l U n i$ versal, 11-12-1998: 1-26).

En lo relativo al mercado laboral el desempleo abierto se ubicó por encima del 10\% como promedio anual a lo largo del período, con cerca de la mitad de la población económicamente activa trabajando en el sector informal de la economía (IESA, 1998). Por otra parte, según los indicadores sociales proporcionados por PROVEA, entre 1993 y 1997 la mortalidad por desnutrición se duplicó para ubicarse en el último año en 993 por cada 100.000 habitantes (PROVEA en Wyssenbach, 1998: 154). En términos del deterioro de los servicios públicos como educación y salud, el $70 \%$ de

1. Un resumen de los principales avatares de la crisis bancaria y financiera del primer año del gobierno de Caldera y de sus programas económicos hasta la Agenda Venezuela puede verse en Editorial Globe (1998: 4/285-325)

2. Para el 11 de diciembre de 1998 el precio de la cesta petrolera venezolana alcanzó la cifra más baja del año al cotizarse en $\$ 7,66$ por barril (Ministerio de Energía y Minas en El Universal, 23-12-1998: 2-1).

3. Al finalizar el año 1998, el Banco Central calculó la inflación en $29,9 \%$, es decir, $20,5 \%$ más baja que el año anterior; las reservas internacionales cerraron en $\$ 14.853$ millones y el dólar se cotizaba a Bs. 565 . El $\mathrm{BCV}$ reconoció que todos estos indicadores eran mejores a "las expectativas que se trazaron para el año" (El Universal, 2-1-1999: 2-4).

4. Para información del deterioro social de los últimos veinte años véase, entre otros, Lander (1996); España (1997); Baptista (1997). 
los estudiantes que ingresan a la educación primaria no llegan a concluir el noveno grado, y 8 de cada 10 alumnos que ingresan a la universidad provienen de la educación privada (Wyssenbach, 1998: 155). En las zonas donde se ubica la población más pobre, la tasa de mortalidad infantil es 2,5 veces más alta que las tasas nacionales; la esperanza de vida al nacer del estrato $\mathrm{V}$, el más pobre, es 12 años menor que el de los estratos I Y II; el Ministerio de Sanidad y Asistencia Social estima que el $30 \%$ de la población no tiene acceso a los servicios de salud (Wyssenbach, 1998: 154). Todo esto revela un cuadro de exclusión, así como un marco poco propicio para abrigar expectativas de mejoría hacia el futuro.

\section{b) El deterioro político-institucional y las promesas incum- plidas sobre reformas}

Así como en lo económico, los ofrecimientos electorales del doctor Caldera no se cumplieron, en lo político-institucional, si bien se alcanzó una cierta paz política, tampoco fue remediada la situación de deterioro de las instituciones fundamentales del Estado y de deslegitimación del sistema político. La ofrecida y anhelada reforma profunda de la Constitución Nacional, que fue una de sus banderas durante la campaña electoral, fue año tras año postergada (Caldera, 1993; López Maya y Gómez Calcaño, 1995).

Es de recordar que Caldera llega al poder luego de una profunda crisis política cuyos hitos más importantes estuvieron representados por la explosión social del 27 de febrero de 1989, los fallidos golpes militares de 1992 y la destitución del presidente Pérez en mayo de $1993^{5}$. Adicionalmente, el desencanto de los venezolanos con su democracia se venía haciendo patente con crecientes índices de abstención en las urnas y con encuestas que revelaban desapego y rechazo hacia la política, los partidos e instituciones como el Congreso y el Poder Judicial (Zapata, 1996: 163-188).

$\mathrm{Si}$ bien es cierto que en los inicios de su gobierno, Caldera conjuró algunas de las más serias amenazas a la estabilidad política, como fueron los casos de distensión logradas con los sectores militares y con el Congreso Nacional, su oferta electoral de producir transformaciones profundas en los poderes del Estado a través de una reforma constitucional fue reiteradamente postergada. En el lustro anterior, una de las propuestas más recurrentes para superar la crisis política institucional fue la de la modificación de la Constitución por vía de una reforma impulsada desde el Congreso o mediante una Asamblea Constituyente. Caldera, en su condición de senador vitalicio presidió la Comisión Bicameral que elaboró una propuesta de reforma amplia que no llegó a ser aprobada por el Congreso. Caldera se ofreció a impulsarla de quedar electo como Presidente (Caldera, 1993) ${ }^{6}$.

A pesar de la promesa, la crisis financiera del año 1994, al combinarse con la debilidad del partido de gobierno y sus aliados en el Congreso, actuó como obstáculo inicial, al poner en riesgo la gobernabilidad. A mediados de 1994, al producirse un impasse entre el Poder Legislativo y el Ejecutivo a raíz del decreto de suspensión de garantías promulgada por éste para enfrentar una masiva fuga de capitales, el Presidente terminó por optar por una alianza con el partido de la primera minoría en el Congreso, Acción Democrática (AD). Esta alianza, nunca formalizada, se prolongaría a lo largo de todo el período constitucional y sería uno de los mayores obstáculos para el avance de cualquier iniciativa profunda de cambios por ser AD el principal defensor del status quo del sistema político. Igual suerte que la reforma general de la Constitución, corrieron también otras iniciativas legislativas, que pudieron haber significado importantes transformaciones en el sistema político e instituciones del Estado. Entre éstas cabe mencionar la reforma parcial a la Ley Orgánica de Régimen Municipal y la Ley de los Derechos Democráticos de los Trabajadores en sus Sindicatos, Federaciones y Confederaciones (El Nacional, 22-11-1998: E-1).

Por otra parte, uno de los campos de actuación del Estado más necesitado de reforma, el Poder Judicial, si bien obtuvo algunas innovaciones en el orden legal, no logró revertir su imagen de ineficacia, ni obtenerse reformas claves como la Ley Orgánica de la Corte Suprema de Justicia, la Ley Orgánica de Salvaguarda del Patrimonio Público, con la cual se lograría el que los delitos de corrupción no pudiesen prescribir, y la del Código Penal. La prescripción en 1997 y 1998 de las causas por delitos contra la cosa pública del ex presidente Lusinchi y su actual esposa Blanca Ibáñez, no hizo más que acentuar el profundo malestar de la ciudadanía por el funcionamiento de este Poder ( $E l$ Nacional, 22-11-1998: E-1).

Finalmente son de destacar las tensiones y peripecias que entre 1997 y 1998 se dieron en torno a la modificación de la Ley Orgánica del Sufragio, ahora llamada Ley Orgánica del Sufragio y de la Participación Política y el nombramiento de los miembros del nuevo ente rector de los comicios, el Consejo Nacional Electoral (CNE). Un seguimiento de las vicisitudes ocurridas durante la discusión de la Ley a lo largo de 1997 hasta su aprobación en diciembre de ese año y del nombramiento del nuevo CNE en febrero del año siguiente, a resultas de un pacto excluyente entre $\mathrm{AD}$ y Copei, los ejes del tradicional bipartidismo venezolano, pusieron en evidencia ante el electorado, una vez más, la escasa voluntad de estos partidos para cambiar sistemas y procedimientos que les favorecían (El Universal, 16-8-1998: 1-16). Por otra parte, la rapidez con que prosperó un acuerdo entre estos mismos partidos para modificar dicha ley cinco meses más tarde, con el fin de adelantar las elecciones regionales y de Congreso Nacional, crear un triunvirato decisorio en el seno del CNE y facultar a ese Consejo para modificar la selección de los integrantes de los organismos subalternos ( $E l$ Universal, 16-8-1998: 1-16), calculando que todo ello favorecería sus intereses, fue otro ingrediente que alimentaría la tendencia a seguir opciones radicales en un electorado hastiado de la reiterativa conducta divorciada de los intereses de la ciudadanía de estos actores.

5. Para un recuento de la crisis política de Pérez, así como de los pasos dados por Caldera en su primer año para superarla, véase Editorial Globe (1998: 4/285-325).

6. Para mayor información sobre el proceso de reforma constitucional que comenzó en 1989 véase entre otros, Kornblith (1993 y 1994; Combellas, 1994 y 1995). 


\section{LA COYUNTURA ELECTORAL: ACTORES EMERGENTES VS. TRADICIONALES}

Los actores emergentes de vocación popular, entendiendo por esto a aquellos que en sus programas políticos y discursos incorporan como eje central de su razón de ser la lucha por las reivindicaciones de los sectores más débiles de la sociedad, además de contar con un contexto socioeconómico y político institucional que los favorecía, a lo largo de la campaña electoral supieron enfrentar con éxito las estrategias y acciones, tanto de las fuerzas tradicionales del bipartidismo, como las de otros actores emergentes. En esta parte presentamos las características de los actores emergentes de vocación popular de esta coyuntura electoral, el MVR y el PPT, quienes conjuntamente con otras fuerzas políticas se aglutinaron en torno al Polo Patriótico, y señalaremos su actuación en los hitos principales de la campaña.

\section{a) El Movimiento V República, el Patria Para Todos y el Polo Patriótico}

El 4 de febrero de 1992 estalla en Venezuela una insurrección militar fallida a cuya cabeza se encontraban un grupo de oficiales medios del ejército hasta ese momento totalmente desconocidos. Este intento de golpe, a diferencia de aquellos ocurridos al inicio de la instauración del sistema democrático a finales de los años cincuenta y comienzos de los sesenta, no fue rechazado por las multitudes en la calle. Una vez que el golpe fue controlado por el gobierno de Pérez, las argumentaciones esgrimidas por los golpistas para justificar su acción, así como la actitud misma que mostraron en las primeras horas de la derrota, despertó una ola de simpatía. Los tenientes coroneles Hugo Chávez Frías y Francisco Arias Cárdenas, el primero, el líder principal de la conspiración y el segundo, quien tuvo a su cargo las exitosas operaciones en la región estratégica del estado Zulia, adquirieron desde entonces una notoriedad política que no los ha abandonado.

Aquí comienza la historia pública del Movimiento Bolivariano Revolucionario 200 (MBR-200), la organización político-militar matriz que dará lugar en esta contienda electoral al Movimiento Quinta República (MVR). La vida del MBR-200 ha sido intensa, y si se quiere singular. Antes de esta fecha y por casi diez años fue una agrupación mayoritariamente militar, que operó en el silencio de los cuarteles, sus dirigentes estudiando y diagnosticando la realidad venezolana para finalmente conspirar contra el orden político establecido $^{7}$. Su nombre le viene de los deseos de emular la conducta y acción de Bolívar y el número 200 se refiere al bicentenario del nacimiento del prócer, celebrado en 1983 , la fecha en la cual ellos dicen haber comenzado sus actividades (Barrera, 18-1-1996; Zago, 1992: 23).

En 1994, pocas semanas después de su toma de posesión como Presidente, Caldera sobreseyó de sus causas a los oficiales de las intentonas de 1992. Fue éste uno de los hábiles pasos dados por el nuevo Presidente en busca de la conciliación y la gobernabilidad. A partir de entonces, el MBR200 pasó a reconstituirse como una organización política de composición cívico-militar, a cuya cabeza Chávez declaró que aspiraría a la Presidencia de la República (El Universal, 27-3-94: 1-1). Sin embargo, no es sino el 19 de abril de 1997 cuando la organización, hasta ese momento abstencionista, decide concurrir a elecciones dentro de los parámetros de la política tradicional. Para ello se hizo de una estructura político-electoral, el MVR. Se cambió el nombre, pues en Venezuela los símbolos patrios, y Bolívar es el principal de ellos, no pueden ser usados como identificación de organizaciones políticas (Nuñez Tenorio, 19-8-1997). Desde 1997, el MVR ha contado con cuadros civiles de dilatada experiencia política proveniente de la vieja izquierda venezolana: Luis Miquilena, José Rafael Nuñez Tenorio, Omar Mezza Ramírez, entre otros (El Universal, 18-10-1998: 1-19).

El Patria Para Todos (PPT), por su parte, se origina de una división de La Causa R (LCR), partido éste que al calor de la transición, en las elecciones de 1993, llegó a convertirse en uno de los partidos principales del sistema político venezolano. La división se produjo en febrero de 1997, cuando el ex gobernador y líder sindical Andrés Velásquez, candidato electoral del partido en las elecciones de 1993, tomó la iniciativa. Después, el grupo de Velásquez, al cual el Consejo Supremo Electoral confirió el nombre y los emblemas de La Causa R, se unió a la candidatura de la ex Miss Universo, Irene Sáez, moderando su discurso para ubicarse en el centro del espectro político venezolano (López Maya, 1998).

La mayoría de los cuadros de LCR pasaron a formar parte del PPT (El Universal, 22-8-1997: 1-16) y a diferencia de lo acontecido entre la dirigencia de LCR, en el PPT se produjo una reafirmación de la orientación popular. El discurso actual del PPT gira en torno a tres ejes temáticos: el nacionalismo, de allí el nombre de la organización, entendido ésto como la defensa de la soberanía en un mundo crecientemente globalizado. Este nacionalismo se expresa en posiciones de resguardo de los recursos estratégicos de la nación, de allí su posición crítica a la política de apertura petrolera, a la privatización de las industrias básicas y su política en torno a la deuda externa. Su vocación popular los lleva también a radicalizar su postura antineoliberal y por último, aunque los consensos alrededor de este tema son menos claros, se sostiene pasar de la democracia representativa a una más participativa, entendiendo por ello, una democracia que abarca los planos de la política, lo económico y lo social (López Maya, 1998). En la medida en que se ha venido dasarrollando el proceso político y electoral, las figuras de Aristóbulo Istúriz, Alberto Müller Rojas, Alí Rodríguez y Pablo Medina, se destacan como los dirigentes principales de este partido.

El MVR y el PPT van a coincidir en algunas de sus propuestas, de manera destacada en el nacionalismo y lo que de allí se deriva, y en su clara vocación popular. Igualmente, estos grupos fueron durante los años críticos del gobierno de Pérez los principales propugnadores de la reforma política profunda a través de una convocatoria a Asamblea Constituyente. De allí que, salvando las diferencias que en

7. Aunque la literatura académica sobre el MBR-200 es escasa, existen algunos textos testimoniales y periodísticos que trazan la historia del movimiento desde 1983. El más completo es el libro de Zago (1992). 
el pasado habían tenido, y después de un proceso de encuentros y desencuentros, se hizo claro que el PPT no tenía otra opción política en esta coyuntura electoral, que apoyar la candidatura en ascenso de Chávez Frías ${ }^{8}$. Ello se formalizó a comienzos de 1998, y el PPT trajo a la candidatura un contingente de experimentados cuadros políticos y sociales. La experiencia política del PPT también ha enriquecido la alianza al incorporar su conocimiento de la política institucional y de la calle del pasado reciente.

Estas dos organizaciones forman el núcleo duro del Polo Patriótico y lo marcan como una alianza de indiscutible vocación popular. Al calor de la coyuntura electoral de 1998, se fueron adhiriendo a este polo otras organizaciones políticas. Es el caso del partido Movimiento Al Socialismo, MAS, cuya dirección hasta inicios de 1998 se debatía entre varias opciones, siendo las principales las que se inclinaban por las candidaturas de Irene Sáez y de Henrique Salas Römer, y en menor medida por Claudio Fermín (El Nacional, 8-2-1998). Una opción muy minoritaria optaba por Chávez. Sin embargo, para mediados de año, varios factores van a pesar para la final decisión del MAS de respaldar la candidatura de Chávez y formar parte de un PP. Por una parte, esta candidatura, si bien débil entre los cuadros de dirección del partido, siempre gozó de amplia simpatía en las bases de éste. En segundo lugar, al producirse el adelanto de las elecciones al Congreso y a las gobernaciones y asambleas legislativas, para el $P P$, una alianza del MVR con el MAS pasó a ser conveniente toda vez que ello permitiría, como de hecho resultó ser, una mejora sustancial de sus posibilidades electorales en ese evento. El MAS cuenta con una importante base regional, expresada para ese momento en cuatro gobernaciones. Para el MAS, el apoyo del PP a sus candidaturas regionales tampoco era de despreciar. Por último, para el momento en que cuaja la alianza, la candidatura de Chávez ya tenía unos meses a la cabeza de la carrera presidencial en prácticamente todas las encuestas. El apoyo del MAS permitiría reforzar esa posición".

Las otras organizaciones que pasaron a engrosar el Polo Patriótico fueron aquellas que en las elecciones de 1993 apoyaron la candidatura de Rafael Caldera, las cuales fueron conocidas como el chiripero. Entre ellas se cuentan al Partido Comunista de Venezuela (PCV) y el Movimiento Electoral del Pueblo (MEP). También se agregarían unos nuevos grupos de electores como: Gente Emergente (GE), Solidaridad Indepediente (SI) y Asociación Agropecuaria (AA). Para septiembre, Chávez contaba, según la encuesta de Datanálisis con $41,6 \%$ de las preferencias del electorado; para octubre con el $44,8 \%$ y para noviembre, después de las elecciones regionales, sube, según esta misma encuestadora a 49,6\% (El Universal, 27-11-98: 1-12). Otras encuestadoras como Consultores 21 le dieron el $46 \%$ de las preferencias electorales tan temprano como en septiembre (El Nacional, 18-09. 1998: A-1) y el 48\% al mes siguiente (El Universal, 14-111998: 1-17).

\section{b) El Polo Patriótico ante la difícil coyuntura electoral}

Al PP se le presentaron en la coyuntura electoral difíciles obstáculos, que supo superar con habilidad y éxito. Los actores políticos tradicionales, especialmente $\mathrm{AD}$ y COPEI, pero también importantes factores de poder, como algunos grupos económicos, importantes medios de comunicación, sectores de las Fuerzas Armadas y personalidades formadoras de opinión, percibieron en la candidatura de Chávez amenaza cierta a un sistema político, del cual en mayor o menor medida, eran usufructuarios. Estos desarrollaron una oposición intensa y a menudo torpe, con lo cual terminaron por favorecer esta opción emergente. Igualmente, los otros actores emergentes sucumbieron temprano o tarde a la alianza con los actores del bipartidismo, lo cual les restó en su imagen del cambio buscado por el electorado.

Desde que lanzara su candidatura en 1997, el estilo discursivo de Chávez, en más de una oportunidad, dio pie para que sus adversarios tomaran elementos con los cuales desatar campañas satanizadoras de su figura. El hecho de que fue responsable de un golpe de Estado, era elemento importante para la construcción de esta imagen. En tal sentido, a lo largo de la campaña en distintas oportunidades, generalmente aprovechando algún desliz discursivo, Chávez fue estigmatizado como autoritario, fascista, anti-democrático, propiciador de la violencia, un candidato que de ganar no titubearía en barrer con las instituciones y desatar un clima de terror que llegaría a una guerra civil. Su mención en un mitin de pueblo de que "barrería a Acción Democrática de la faz de la tierra" o de que de ganar la cabeza de los adecos y copeyanos serían "fritas"; o sus declaraciones en el sentido de que aquellos que se opongan a la convocatoria a una constituyente irán a la cárcel, despertó justificadamente airadas manifestaciones de repudio (ver, por ejemplo, El Nacional y El Universal, 25-11-1998: D-4 y 1-12). Sin embargo, la torpeza con que los partidos ejes del bipartidismo quisieron capitalizar estos dislates, terminó neutralizando las palabras de Chávez o en algunos casos incluso beneficiándolo. Tal fue el caso, por ejemplo, de una propaganda de AD transmitida por los medios audiovisuales, donde se presentó una imagen ofensiva de personas humildes. Estos vociferaban, frente a un caldero lleno de aceite, que tendrían que freir a toda Venezuela porque todos "somos adecos". La cuña fue censurada y retirada por el CNE, pero además de los chistes que estimuló, dejó una impresión de repudio hacia $\mathrm{AD}$ entre diversos sectores sociales.

Una fuente importante de tensiones se produjo con algunos sectores castrenses, cuya cabeza más visible fue el comandante del Ejército, general Rubén Rojas Pérez, yerno del presidente Caldera. Las manifestaciones más notorias de este desencuentro tuvieron lugar a partir de octubre y llegarían hasta las elecciones de diciembre. El general Rojas en su intervención durante un acto del ejército en la ciudad de Maturín manifestó que este cuerpo no podría aceptar el triunfo electoral de quien había encabezado un golpe militar (José

8. Los vínculos entre ambas organizaciones datan de antes de la insurrección militar del 4 de febrero (Conversación informal con Pablo Medina, Nueva York, febrero, 1997; Entrevista a Hugo Chávez, Caracas, 25-3-1996). Luego de esa intentona se distanciaron por diferencias en torno a la misma. Esta coyuntura electoral los ha vuelto a juntar.

9. En la publicación de los sondeos realizados en abril, Chávez pasa al primer lugar en todas las encuestas (Sanoja, 1998: 224-225). 
Vicente Rangel en El Universal, 11-10-1998: 1-12). Días antes de estas palabras, ya se había producido un impasse al negarse este mismo comandante a asistir a la reunión del Alto Mando Militar con el candidato presidencial Chávez. El Alto Mando venía, por propia iniciativa, convocando reuniones con todos los candidatos (El Universal, 9-10-1998: 1-20). Otros sucesos de este tenor perturbaban el clima electoral y hacían presagiar la posibilidad de un desenlace violento. En los días inmediatamente anteriores a los comicios presidenciales, se corrieron insistentes rumores sobre una salida militar para impedir el triunfo de Chávez. El presidente Caldera se mantuvo mayormente al margen de esta confrontación, sin embargo, en momentos decisivos, como el viernes 4 de diciembre, dos días antes de las elecciones presidenciales y en medio de los peores rumores, en un acto de fin de año de la Guardia Nacional, un cuerpo que los rumores vinculaban estrechamente con el golpe, hizo claro que el gobierno garantizaría el respeto a los resultados electorales y a la institucionalidad democrática. Este discurso fue trasmitido en cadena nacional, cosa nada frecuente para este tipo de actos ( $E l$ Nacional, 5-12-98: D-2).

Con menos estridencia, pero igualmente fuertes, resultaron las tensiones entre el PP y Petróleos de Venezuela (PDVSA). En este caso, buena parte de los críticos y opositores de la política petrolera que en años recientes ha venido impulsando PDVSA terminaron agrupándose, más o menos activamente en el Polo. El único candidato que expresó sus desaveniencias con la política de la industria fue Chávez (El Nacional, 18-9-1998: D-1; El Universal, 10-101998: 1-14). Esto le significó que voceros de la industria, así como otros sectores del país opuestos a Chávez, participaran en la campaña de oposición al candidato acusándolo de ignorante, estar mal asesorado y de defender posturas ya superadas (Rial en El Nacional, 13-10-1998; Monaldi en El Nacional, 1-11-1998)). Sin embargo, en la situación de precios petroleros deprimidos y de sobreoferta, las críticas a la política expansiva de PDVSA encontraron más receptividad y simpatía que en años anteriores.

Finalmente, al calor de la campaña y ante el sostenido ascenso de Chávez en las encuestas, éste se fue configurando como el candidato a vencer por las restantes opciones. Cada uno de los otros candidatos fue diseñando estrategias que le permitieran aglutinar a su alrededor las voluntades anti-chavistas. Esto, sin embargo, no fue posible antes de las elecciones regionales de noviembre, ya que no quedaba claro de las encuestas y sondeos de opinión, quién era el candidato más idóneo para confrontarse con éxito con el candidato del PP. Sin embargo, estos múltiples y frontales ataques también daban a su imagen cirtos rasgos de víctima.

Pasadas las elecciones regionales, en noviembre el cuadro electoral pareció definirse en tres bloques: por una parte el Polo Patriótico, por otro el Proyecto Venezuela que aupaba la candidatura de Salas Römer, que si bien sus resultados habían sido magros, en las encuestas comenzaba a distanciarse de los otros candidatos que disputaban el segundo lugar: Luis Alfaro Ucero por AD e Irene Sáez por COPEI, Movimiento IRENE y Factor Democrático. Ante esta realidad, AD y su candidato idearon una ofensiva publicitaria para presentarse como los triunfadores de noviembre y potenciar así su candidato presidencial ${ }^{10}$. AD había obtenido la fracción parlamentaria más numerosa, medido como partido individual, y había retenido ocho gobernaciones (CNE, 1998).

Aunque la idea de conformar un Polo Democrático había sido manejada antes, no había cuajado. Pero para sorpresa del país, a partir del 24 de noviembre comienzan a precipitarse una cadena de sucesos que culminarán con la concentración mayoritaria de las organizaciones no chavistas alrededor de la candidatura de Salas Römer.

En efecto, el 24 de noviembre, un grupo de gobernadores de $\mathrm{AD}$ recién electos plantean ante la Comisión Nacional de Estrategia de su partido, reconsiderar la candidatura de Alfaro (El Universal, 25-11-1998: 1-12). Ese día la propuesta fue rechazada. Al día siguiente, en reunión del Comité Ejecutivo Nacional (CEN) con los gobernadores adecos, con una votación de 39 votos a favor y 5 en contra, se le pide al candidato su renuncia, a la cual éste se niega $(E l$ Nacional y El Universal, 26-11-1998: D-1 y 1-2). Ante tal negativa, el CEN decide convocar para el día 27 a un Comité Directivo Nacional (CDN), que con enfrentamientos físicos incluidos decide revocar la candidatura de Alfaro ( $E l$ Universal, 28-11-1998: 1-1). El día 28 el CEN ordena a su militancia votar por Salas Römer (El Nacional, 29-11-1998: D-2). Concluye este episodio con la expulsión por decisión unánime de los miembros del CEN de Alfaro Ucero, quien se negó a acatar las decisiones de las distintas instancias de su partido. También ocurrió la polémica decisión del Consejo Nacional Electoral de valer los votos emitidos con la tarjeta de AD para Salas Römer (El Universal, 1-12-1998: A-1)".

Mientras esto ocurría en $\mathrm{AD}$, en COPEI se fueron sucediendo los hechos que culminarían con el apoyo de ese partido también a Salas Römer, en secuencia retardada a los acontecimientos que se desarrollaban en AD. La dirección nacional de este partido, en reunión del 30 de noviembre, decide revocar la candidatura de Irene Sáez y sumarse a la de Salas Römer (El Universal, 1-12-1998: 1-2). Los dos candidatos defenestrados deciden continuar en la campaña apoyados por otros grupos de electores.

Estos atropellados acontecimientos de última hora, para conformar un frente electoral anti-Chávez, como fue demostrado en las elecciones del 6 de diciembre, lejos de poner en peligro el triunfo del candidato del PP pareció reafirmarlo. Pues así como en su momento la candidatura independiente de Irene Sáez acentuó su declive en los sondeos de opinión al oficializarse el apoyo, primero del partido COPEI y posteriormente de la alianza para planchas parlamentarias del Distrito Federal con AD, así mismo, este apoyo de última hora de AD y Copei a la candidatura de Salas Römer, si bien sería aventurado afirmar que la debilitó o perjudicó, a

10. En los principales periódicos del país, el día 9 de noviembre aparecieron grandes avisos publicitarios que decían: "Se demostró - AD - Somos la mayoría - Alfaro Presidente".

11. Hubo interpretaciones encontradas alrededor del artículo 151 de la ley, por cuanto éste expresaba que para sustituir una postulación hacía falta la renuncia, muerte o una declaración de incapacidad del candidato, nada de lo cual ocurría en este caso. Miembros del CNE y consultores jurídicos de ese organismo, días antes habían declarado la imposibilidad de la transferencia de los votos, si Alfaro no renunciaba (El Nacional, 18-11-1998: D-1; 27-11-1998: D-6 y 29-11-98: D-6). 
la vista de los resultados bien puede decirse que no la benefició. La torpeza e improvisación de los actores políticos tradicionales del bipartidismo ahondaron en el rechazo hacia ellos, abonando con ello la opción que más claramente garantizaba el cambio.

\section{LOS RESULTADOS ELECTORALES DEL POLO PATRIÓTICO}

Separadas en mayo por el Congreso las elecciones presidenciales del resto, mediante una alianza exclusiva entre AD y COPEI, el 8 de noviembre se realizaron los comicios para elegir senadores y diputados al Congreso Nacional, gobernadores para los veintitrés estados, y diputados a las asambleas legislativas de éstas. Para estas elecciones se dieron alianzas de diversa naturaleza entre los partidos y agrupaciones electorales, explicándose algunas de ellas por lógicas regionales. Sin embargo, la anticipación de estos comicios con respecto a la elección presidencial, que quedó para el 6 de diciembre, determinó que los resultados de noviembre fueran interpretados como "una primera vuelta" de la presidencial. A continuación destacaremos el desempeño de los candidatos del $P P$ en ambos comicios.

\section{a) Las elecciones de noviembre}

Para el 8 de noviembre, las principales agrupaciones políticas que constituían el PP, es decir el MVR, PPT y MAS lograron acordarse para llevar candidatos comunes a las elecciones regionales. Esto reflejó la voluntad y capacidad de estos partidos para hacer a un lado sus intereses particulares en función de los más generales de la alianza. Gracias a ello, los candidatos a gobernador del PP resultaron electos en ocho estados (véase Cuadro I).

CUADRO I

GOBERNADORES ELECTOS DEL POLO PATRIOTICO noviembre de 1998

\begin{tabular}{||l|c|c|c||}
\hline \hline GOBERNADOR & ESTADO & VOTOS & $\%$ \\
\hline \hline Alexis Rosas & Anzoátegui & 92.175 & 34,22 \\
\hline Didalco Bolivar & Aragua & 229.211 & 67,59 \\
\hline Hugo de los Reyes Chávez & Barinas & 68.070 & 43,55 \\
\hline Eduardo Manuitt & Guárico & 81.259 & 48,00 \\
\hline Orlando Fernandez & Lara & 178.697 & 53,53 \\
\hline Iván Colmenares & Portuguesa & 88.038 & 47,34 \\
\hline Alfredo Laya & Vargas & 32.698 & 39,17 \\
\hline Francisco Arias Cardenas & Zulia & 325.968 & 54,42 \\
\hline
\end{tabular}

Fuente: Consejo Nacional Electoral, http.//www.eleccion98.cantv.net, [fecha 28-12-1998]

Además de estas victorias, que lós igualaron en número de gobernaciones con el partido AD, la alianza llegó en segundo lugar en diez de las trece gobernaciones restantes. Si bien en el Distrito Federal no se elige gobernador, el desempeño allí del $P P$ fue arrolladoramente triunfante en la elección de los cargos al Congreso Nacional (véase Cuadro II). Tomando en cuenta que las previsiones en $\mathrm{AD}$ eran que, en el peor de los casos, ellos retendrían sus once gobernaciones obtenidas en 1995, pudiendo llegar a aumentar hasta catorce, los resultados arrojaron un saldo claramente favorable al PP (El Universal, 12-10-1998: 1-10). Tómese en cuenta además, que el total de la votación de los gobernadores electos del PP fue de 1.096.116, mientras que el de los gobernadores de AD alcanzaba sólo 564.391. Resultó sorpresiva y emblemática la elección del padre de Hugo Chávez como gobernador del Estado Barinas derrotando al gobernador en ejercicio de AD. También fue contundente el triunfo de Alexis Rosas del PPT en Anzoátegui, donde compitió contra el ex-candidato presidencial de La Causa R, Andrés Velásquez, llegando éste de tercero, tras el candidato de $\mathrm{AD}$. Además de Rosas, del PPT resultaron electos gobernadores Eduardo Manuitt y Alfredo Laya en Guárico y Vargas, que aunado a su bancada parlamentaria, le proporciona a este partido un sólido espacio político para reconstruirse después de la división de LCR año y medio atrás.

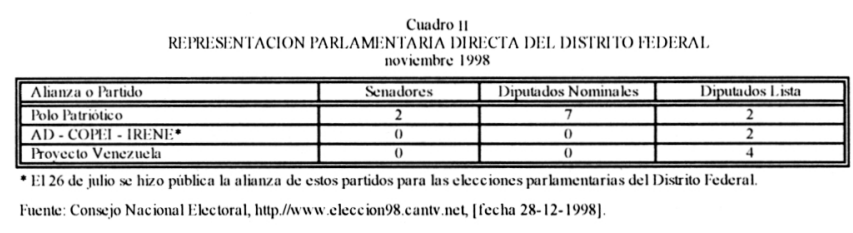

Pese a los resultados contundentes para el $P P$ en su representación paralamentaria para el Distrito Federal, los resultados parlamentarios en el resto del país, sin ser contrarios, no le confirieron una mayoría hegemónica en el Congreso. En efecto, el Congreso Nacional que se instaló el 23 de enero de 1999 está conformado por una variedad de fuerzas políticas, ninguna de las cuales es mayoría sola y será necesario para adelantar cualquier iniciativa legislativa establecer alianza entre dos o más de estas fuerzas parlamentarias. El PP cuenta con aproximadamente un tercio de la representación en el senado y un poco más en la Cámara de Diputados (véase Cuadro III).

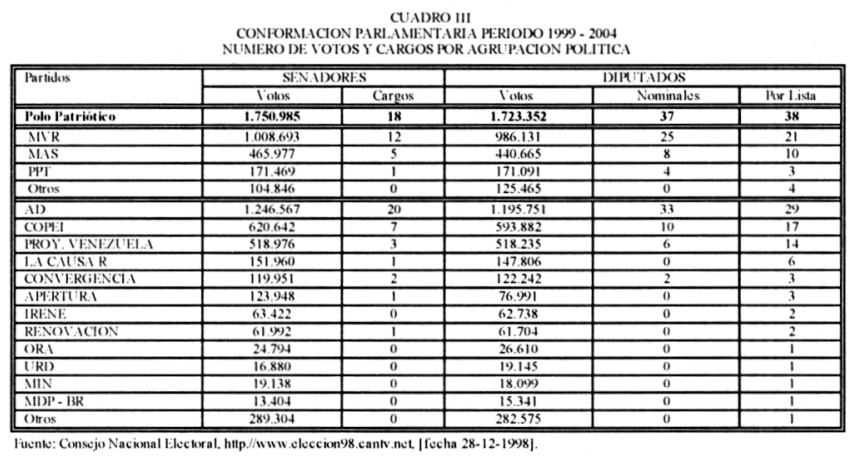

Estos resultados, por una parte, dieron pie a que los adversarios del $P P$ buscaran afanosamente en el mes de noviembre constituir un polo electoral alternativo para los comicios presidenciales, argumentando que dos terceras parte del país se habían manifestado en contra de los candidatos y propuestas de Chávez Frías. Especialmente, la idea de una reforma profunda del Estado por la vía de una Asamblea Constituyente, propuesta central de la oferta electoral del MVR y del Polo Patriótico, pareció debilitarse toda vez que emergía un Congreso con una composición mayoritariamente contraria a ella ${ }^{12}$.

12. Como ilustración, valgan las declaraciones dadas el 15 de noviembre por el senador reelecto por COPEI, Edgar Flores: "Las reformas se harán desde aquí [el Congreso Nacional]". También las del senador reelecto por AD, Pedro Tábata Guzmán: “Chávez no podrá instalar, si gana, la asamblea constituyente de la manera como lo pretende hacer"... (El Nacional, 15-11-1998: H-1). 
Sin embargo, después de la cadena de acontecimientos ya señalados en el apartado segundo, que resultaron en la constitución aparatosa del llamado Polo Democrático en torno a la figura de Henrique Salas Römer, el 6 de diciembre, los comicios arrojaron el resultado siguiente:

CUADRO N IV

RESULTADOS DE LAS ELECCIONES PRESIDENCIALES diciembre 1998

\begin{tabular}{||l|c|c|}
\hline \hline CANDIDATO & VOTOS & $\%$ \\
\hline Hugo Chávez Frias & 3.673 .685 & 56,20 \\
\hline Henrique Salas Römer & 2.613 .161 & 39,97 \\
\hline Irene Saez Conde & 184.568 & 2,82 \\
\hline Luis Alfaro Ucero & 27.586 & 0,42 \\
\hline otros & 38.304 & 0,58 \\
\hline
\end{tabular}

Fuente: Consejo Nacional Electoral, http.//www.eleccion98.cantv.net, [ fecha 3-1-1999].

La holgada victoria de Hugo Chávez Frías ganando en 18 de las 24 entidades federales, si bien prevista por algunas encuestas, no dejó de despertar sorpresas. Como puede verse en el Cuadro IV, se produjo una acentuada polarización $(96,17 \%)$, en la cual el PP superó el $50 \%$ de los votos. Después de haber capitalizado en noviembre la tercera parte de los votos, los resultados pueden explicarse a partir de varios hechos. Por una parte, aumentó, como era de preverse, la participación electoral en $9,25 \%^{13}$. Esto significó un aumento de las masa de votantes del orden de 1.103.703 votos. Las votaciones de los partidos Proyecto Venezuela, $\mathrm{AD}$, COPEI, Convergencia, es decir, de quienes mandaron a sus militantes y simpatizantes a votar por la candidatura de Salas Römer, en diciembre obtuvieron sólo cien mil votos más a la que en conjunto les fue registrada en noviembre, mientras Chávez sacó 1.922.700 votos más. Ello indica que, en primer lugar, la disminución en la abstención se volcó muy mayoritariamente a favor de Chávez. En segundo lugar, los electores, que en las elecciones de noviembre votaron por organizaciones políticas que no se plegaron a la opción de Salas Römer, también terminarían mayoritariamente votando por el candidato del MVR, sin que esto fuera resultado de nuevas alianzas formales ${ }^{14}$. En este sentido, Chávez fue también más favorecido que Salas por la polarización. En tercer lugar, el clima de entusiasmo y politización del país en los meses recientes, permitían anticipar una abstención en las elecciones presidenciales menor a la finalmente registrada. Una hipótesis para explicar esto, imposible de cuantificar con las cifras oficiales del CNE, es que el número de votantes de las elecciones de noviembre que no lo hicieron en diciembre, principalmente entre los de AD y COPEI y como acto de repudio a la conducta de las cúpulas de esos partidos, pudo haber sido elevada. De ser cierta esta hipótesis, el número de nuevos votantes en diciembre es superior a la registrada en la cifras oficiales como simple diferencia entre el total de votantes en ambos comicios. Este sería un caudal adicional de votos que favorecieron a Chávez.

\section{COMENTARIOS FINALES}

La victoria de Chávez Frías y el Polo Patriótico cabalgaron sobre la transición irresuelta de la sociedad venezolana. Una situación de incertidumbre con respecto al porvenir, que se agravó al iniciarse 1998 por la insistente baja de los precios petroleros, hicieron ver los pregonados logros económicos de la Agenda Venezuela del gobierno de Caldera como coyunturales, abriendo de nuevo el pesimismo y el cuestionamiento al rumbo trazado. Junto a esta variable, si bien no se vivieron los años de zozobra de los presidentes Pérez y Velásquez, tampoco se vio mejoría en la calidad de vida, ni recuperación del deterioro político-institucional. Por otra parte, en 1998 se hizo más visible que en otros años la escasa o nula voluntad de los actores de la política tradicional de alterar las reglas de juego. Quizás por todas estas razones, a principios de año, los estudiosos pronosticaban una abstención del $50 \%$ en las elecciones de diciembre y la continuación de la apatía política (Sanoja, 1998: 239).

La candidatura de Chávez Frías y las fuerzas que se aglutinan a su alrededor, introducen en la contienda la esperanza de un cambio profundo, tanto de la clase política como de las propuestas de país hasta entonces presentadas. Su discurso, además, es el único que le da preeminencia a los sectores empobrecidos y excluidos, y los valora como sujetos del sistema político democrático. Así, la polarización social creciente encuentra en Chávez su expresión política. Por otra parte, su hábil manejo de los emblemas y símbolos patrios, estimula una muy necesitada autoestima entre los venezolanos, quienes llevan cuatro lustros asistiendo a una regresión de su proceso de modernización en el siglo XX.

Los resultados de diciembre de 1998, con mayor radicalidad que los de 1993, abren para la sociedad venezolana un mapa político nuevo. El desempeño de AD y COPEI parece dejar atrás, de manera definitiva, el bipartidismo fundamentado en el Pacto de Punto Fijo. Con los actores emergentes, tanto los de vocación popular, como los otros, irrumpen en el escenario nuevos rostros y parece predominar finalmente nuevas generaciones en el liderazgo político.

Al tomar posesión de la Presidencia, Chávez se encontrará con retos significativos. Por una parte, deberá lograr el difícil equilibrio entre las expectativas de cambio, nítidamente expresadas en el resultado electoral, con la necesaria construcción de consensos que la permanencia y consolidación democrática requieren. El primer lugar; donde ya se está expresando esta tensión, es en la definición del camino para llegar a la Asamblea Nacional Constituyente. Chávez deberá desplegar pulso político para minimizar y derrotar a los intransigentes ante cualquier propuesta, neutralizar o convencer a los menos renuentes, pero no ganados a lo nuevo, y fortalecer y consolidar aquellas fuerzas que propician las reformas.

Desde que fuese proclamado como presidente electo, Chávez ha obtenido éxitos en desatanizar su imagen. Sin abandonar los principales elementos de lo que ofreció como acción de gobierno, ha ido estableciendo una red de relaciones y desarrollando un estilo que le han permitido ser visto ahora como más receptivo y abierto al diálogo. No obstante, muchos obstáculos quedan por superarse y ha

13. La abstención en las elecciones para senadores fue de $45,49 \%$ y en las presidenciales de $36,24 \%$ (CNE, 1998).

14. El politólogo Boris Bunimov Parra en su artículo publicado en El Nacional (22-12-1998: A-5), desarrolla una argumentación similar, que en lo fundamental compartimos. 
habido posturas, como la intención de invitar al ex dictador Marcos Pérez Jiménez a su toma de posesión, que crean aprensión y repudio que no ayudan. Así mismo, para los sectores más conservadores de la sociedad, la llegada de estas nuevas fuerzas son percibidas con temor y rechazo. Entre éstos se oyen comentarios que denotan prejuicios sociales y hasta raciales, poco frecuentes en el debate público venezolano de la etapa democrática, que dan cuenta de los cambios que cuatro lustros de deterioro han propiciado. Afirmaciones como "somos el país con la cultura política más deleznable del continente y uno de los países más tristes del mundo"... (Rafael Arráiz Lucca en El Nacional, 13-11-1998: A-6) retrata a una élite que se resiste a reconocer como legítima la emergencia de nuevos actores con tanta valía como los que puedan estar siendo desplazados. En este sentido, y aunque el presidente electo no ha estado dispuesto a reconocerlo, la emergencia de las nuevas fuerzas que en él y el $P P$ se representan, guardan innegable analogía con las que en octubre de 1945 se aglutinaron en torno a Acción Democrática. Tanto entonces como ahora se oyeron las voces escandalizadas de quienes en los sectores populares y sus líderes sólo veían ignorancia, primitivismo e inferioridad. En 1947 se afirmaban cosas como: "Imagínese que Mateo dice que esto es como el paraiso de los bichos, y el infierno de la gente buena" (Pino Iturrieta, 1995). Hoy bien ridiculiza este temor el caricaturista Pedro León Zapata al estampar en una de sus caricaturas de noviembre: "No es por Rambo, es por zambo". En este nuevo ciclo que se abre, le toca a los actores emergentes de vocación popular no volver a equivocar el camino.

\section{REFERENCIAS}

BAPTISTA, Asdrúbal (1989): "Tiempos de Mengua. Los años finales de una estructura económica”. En: Pedro Cunill Grau y otros, Venezuela Contemporánea. Caracas: Fundación Eugenio Mendoza: 105-156.

- (1997): "Crecimiento económico y distribución del ingreso”. En: Sic, año LX, N. 600: 484-487.

CALDERA, Rafael (1993): Mi carta de intención con el pueblo de Venezuela. Caracas. S/e.

CNE (1998): Elecciones 1998. En http://www.eleccion98.cantv.net [fecha 28-12].

COMBELlas, Ricardo (1994): Una Constitución para el futuro. El debate constitucional en Venezuela. Caracas. Editorial Panapo.

- (1995): La reforma integral del Estado y los retos de la COPRE para el quinquenio. Caracas. Ediciones de la COPRE. marzo.

Editorial Globe (1998): La Gran Enciclopedia de Venezuela, T. 4. Caracas: Editorial Globe C.A.
EsPaña, Luis Pedro (1997): "Dos décadas de empobrecimiento y pobreza en Venezuela”. En Sic, año LX, N. 600: 480-483.

KornBLiTH, Miriam (1994): "Viabilidad y deseabilidad de la Reforma Constitucional en Venezuela: el intento de 1989-92 y el proceso actual". Ponencia presentada en el Seminario: Foro Reforma Constitucional (COPRECiedla-Fundación Konrad Adenauer). Caracas, junio.

- (1993): "Reflexiones críticas sobre los intentos de reforma constitucional en Venezuela (1989-1992)”. En: El Derecho Constitucional en el umbral del siglo XXI, Asociación Venezolana de Derecho ConstitucionalInstituto de Derecho Comparado de la Universidad de Carabobo, Valencia (Venezuela), pp. 313-348.

IESA (1998): "Desempleo e Informalidad". En http://www. iesa.edu.ve/MACROECONOMIA [fecha 29-12].

- (1999): "IPC General"; "Reservas Internacionales Brutas" y "PIB total". En http://www.iesa.edu.ve/MACROECONOMIA [fecha 2-1].

LANDER, Edgardo (1996): Neoliberalismo, sociedad civil y democracia. Ensayos sobre América Latina y Venezuela. Caracas: Ediciones de la Universidad Central de Venezuela.

LÓPEZ MAYA, Margarita (1998): "Problemas de los partidos populares en la transición (tras una alternativa política en Venezuela)". En: Contribuciones, 1/1998: 79-106.

LÓPEz MAYa, Margarita y Edgardo LANDER (1996): "La transformación de una sociedad 'petrolera-rentista': desarrollo económico y viabilidad democrática en Venezuela”. En: Pilar Gaitán, Ricardo Peñaranda, Eduardo Pizarro (compiladores), Democracia y reestructuración económica en América Latina. Bogotá: Cerec: 159-188.

LÓPEZ MAYA, Margarita y Luis GómEz CALCAÑo (1996): "¿Por qúe no avanza la reforma constitucional? Partidos, actores sociales y medios". En: Revista Venezalana de Economía y Ciencias Sociales, N. 2-3: 57-84.

NaIM, Moisés (1993): Paper Tigers E Minotaurs. The Politics of Venezuelas Economic Reforms. Washington: The Carnegie Endowment for International Peace.

PinO ITURRIETA, Elías (1995): "Movimiento de Rotación". Ponencia presentada en el evento La Revolución de Octubre 1945 - 1995, Caracas: Fundación CELARG Fundación Rómulo Betacourt, octubre.

Sanoja Hernández, Jesús (1998): Historia Electoral de Venezuela 1810-1988. Caracas: Los Libros de El Nacional, Editorial CEC.

WySSENBACH, Jean Pierre, "Venezuela 1997". En: Sic, año LXI, N. 604: 152-156.

ZAPATA, Roberto (1996): Valores del venezolano. Caracas: Consultores 21.

ZAGO, Angela (1992): La rebelión de los ángeles. Caracas: Fuentes Editores. 


\section{RESUMEN}

En este artículo se examina el desempeño de los actores emergentes de vocación popular en las elecciones venezolanas de 1998. Se sostiene que los comicios estuvieron condicionados, por una parte, por un contexto socioeconómico y político que creó en el electorado una favorable actitud hacia el cambio radical. Por otra parte, al examinar los principales hitos de la campaña y las relaciones y respuestas de los actores participantes en la contienda, tanto los tradicionales como los nuevos, se evidencia la habilidad con que se desenvolvió el candidato Hugo Chávez Frías y el Polo Patrótico, frente a sus adversarios. Por último, se presentan y evalúan los resultados electorales, cerrando con unas conclusiones sobre la situación y desafíos que se presentan a estos actores en el futuro inmediato.

Palabras clave: Elecciones venezolanas 1998, Polo Patriótico, Movimiento Quinta República, Patria Para Todos, Proceso sociopolítico venezolano, Hugo Chávez Frías.

\section{ABSTRACT}

In this article we examine the performance of emergent popular actors in Venezuela's 1998 elections. We argue that the triumph of Hugo Chávez and his Polo Patriótico is a result of a particular socioeconomic and sociopolitical context that drove venezuelans to support a radical change in the political system. This general situation was combined with smart decisions and attitudes of the Polo Patriótico with regard to its opponents during the campaign. We present the results of regional and Congress elections of November as well as the presidencial results of Dicember, closing with comments about today's situation and future challenges.

Key words: Venezuela's 1998 elections, Polo Patriótico, Movimiento Quinta República, Patria Para Todos, Venezuela's Sociopolitical Process, Hugo Chávez Frías.

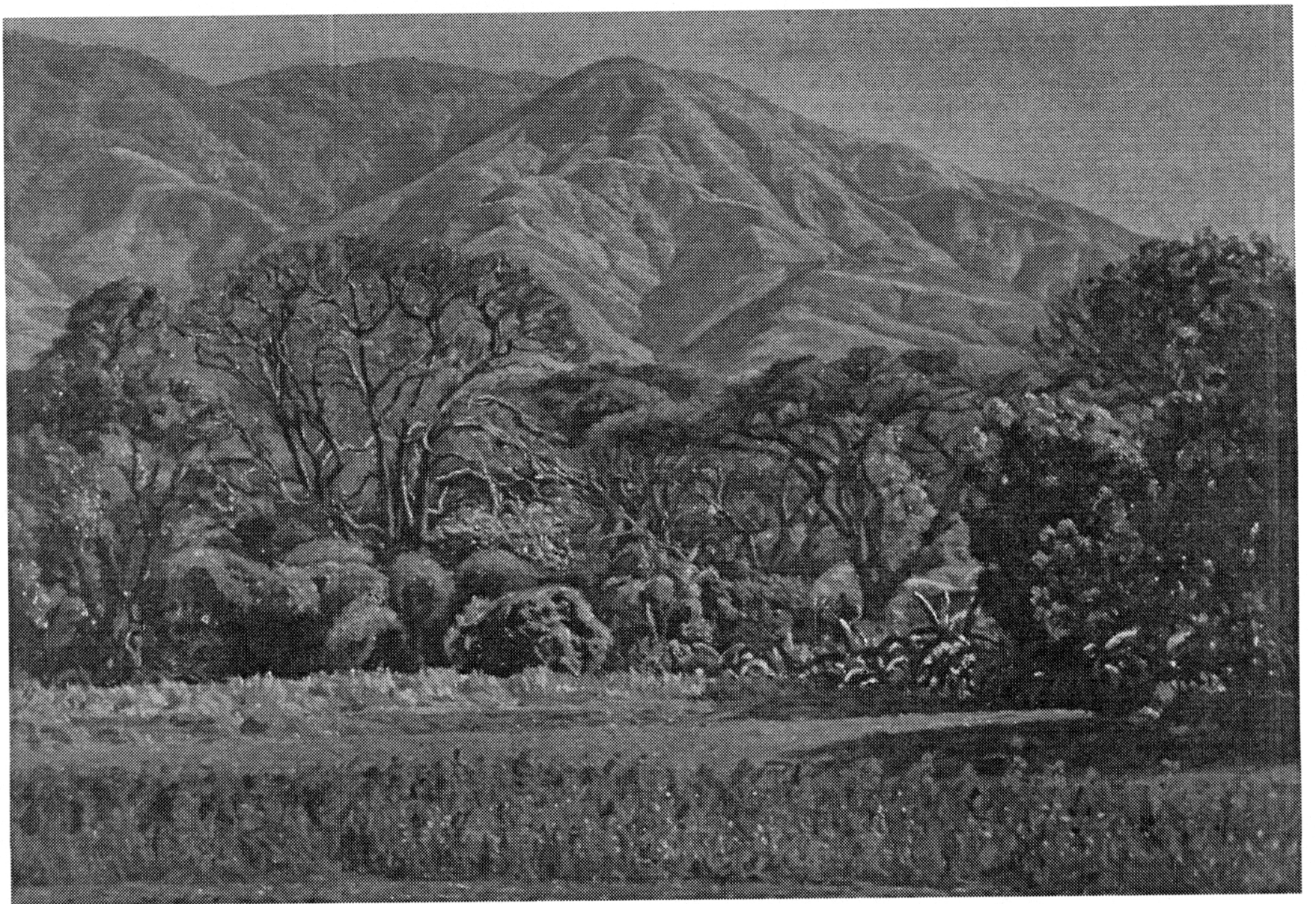

"Verano", Manuel Cabre 